\title{
CONSERVAÇÃO DA BIODIVERSIDADE: ESPÉCIES DA FLORA DE MATO GROSSO*
}

\author{
Eliani Fachim ${ }^{1}$ \\ Vera Lucia M.S. Guarim²
}

Recebido em 24.02.94. Aceito em 20.10.95.

\begin{abstract}
RESUMO: O Brasil possui a flora mais rica do globo com cerca de 60.000 espécies conhecidas. Mato Grosso participa com uma parcela significativa, por conter diferentes regiões biogeográficas: a amazônia, o cerrado e o pantanal - diferenciados tanto pela estrutura quanto pelas espécies. A metodologia utilizada neste trabalho buscou verificar a vulnerabilidade das espécies e ecossistemas, com base no modelo recomendado pelo IICA (Instituto Interamericano de Cooperação em Agricultura ) e o sistema de classificação das categorias segundo a União Internacional para Conservação da Natureza e Recursos Naturais (IUCN). As espécies selecionadas foram distribuídas em seções: madeireira, medicinal, frutíferas, ornamental e palmeiras. São apresentadas 37 espécies da flora de Mato Grosso, enquadradas nas categorias: Vulneráveis (V), Em Perigo de Extinção (E), Rara (R). O extrativismo das espécies converge para o objetivo da importância conservacionista.
\end{abstract}

Palavras Chave: Conservação, Biodiversidade, Flora de Mato Grosso, Espécies ameaçadas.

ABSTRACT: (Biodiversity Conservation: Species from Mato Grosso Flora.) Brazil prossesses the richest flora on the world, counting with around 60.000 known species. Though having diverse biogeographic regions [the "amazon cerrado" and the "pantanal"], differenteated both by structure as well as by species, Mato Grosso state participantes participates significantly. The working process herein used aimed at checking the vulnerability of species and ecosystems based on the model recomended by the IICA (Interamerican Institute for Cooperation in Agriculture) and system of category classification according to the International Union for the Conservation of Nature and Natural Resources [IUCN]. Selected species were sorted by section: wood source, medicinal, fruitbearing, ornamental and palm 37 species of the Mato Grosso flora are presented, placed in the categories: Vulnerable [V], Endangered [E] and Rare [R]. Extraction from the species converges towards the objective of a conservacionist importance.

Key Words: Conservation, biodiversity, Mato Grosso flora, In dangerous of extinction.

\footnotetext{
* Parte da Monografia de Graduação em Ciências Biológicas - IB / UFMT.

${ }^{1}$ Bióloga - Fundação Estadual do Meio Ambiente - Divisão de Unidades de Conservação.

2 Professora Adjunto. Departamento de Botânica e Ecologia. IB / UFMT.
} 


\section{Introdução}

Através de estudos, começou-se a avaliar até que ponto o homem precisa preservar outras espécies, inclusive aquelas que utiliza para sua subsistência, e qual a necessidade que algumas delas têm, em relação à outras, para sobreviverem.

O conhecimento humano a respeito da natureza, tem se aprofundado nas últimas décadas e isso levou a uma reformulação de muitos conceitos, inclusive a importância científica do estudo dos ecossistemas, com toda a sua riqueza e diversidade. Foi criado, assim o conceito de BIODIVERSIDADE.

Segundo Fonseca (1991), a idéia da Biodiversidade é ampla, pois incorpora também a diversidade de raças e variedades, e permite definir a diversidade comparativa entre os ecossistemas e habitats.

O Brasil é considerado megadiverso, porque possui um patrimônio genético incomparável nos seus mais ricos ecossistemas. Uma de suas principais características é estar relacionado aos expressivos níveis de endemismos e, estes, basicamente, à grande diversidade de habitats e à extensão territorial do país.

Segundo Forero (1989), o Brasil tem uma das floras mais ricas do mundo com 50.000 espécies.

Giulietti \& Forero (1990) consideram o Brasil como país de flora mais rica do globo com cerca de 60.000 espécies. Tal fato está, certamente, relacionado a vasta extensão territorial, diversidade climática, edáfica e geomorfológica, produzindo como resultado final uma grande diferenciação vegetacional.

O Estado de Mato Grosso, com seu vasto espaço territorial, está caracterizado por três regiões biogeográficas - a amazônica, o cerrado e o pantanal — diferenciados, tanto pela estrutura, como pelas espécies e densidade de indivíduos por hectare, ostentando uma situação privilegiada, no que se refere a potencialidade dos recursos naturais.

O acelerado processo de ocupação territorial do Estado, com o avanço de suas fronteiras agrícolas e, fortalecimento dos setores produtivos, tem exercido um forte impacto sobre o meio ambiente, não só em decorrência das atividades extrativistas, mas, também, daquelas originárias da intensificação do uso do solo, atingindo os ecossistemas e, conseqüentemente a variabilidade de espécies, levando-as à extinção.

Sob a proteção do Estado, estão cinco unidades de conservação, sem contabilizar as reservas indígenas, abrangendo uma área de cerca de 411.025 ha, representando uma pequena porção territorial do Estado de Mato Grosso.

O presente trabalho tem a intenção de, através das regiões biogeográficas no Estado de Mato Grosso, citar algumas espécies vulneráveis ou ameaçadas de extinção, devido as ações antrópicas e propor sua conservação em seus respectivos ecossistemas. 


\section{Metodologia}

Com base no modelo recomendado pelo IICA (Instituto Interamericano de Cooperação em Agricultura), os métodos de seleção das espécies obedeceram a uma classificação dentro de:

a) Distribuição ecológica restrita;

b) Baixa densidade de população (geral - local);

c) Alta exploração de madeiras, plantas medicinais, ornamentais e alimentícias;

d) Habitats vulneráveis ou ameçados de extinção;

e) Vulnerabilidade de espécies que dependem de outras para sobreviver.

Além destes métodos, utilizou-se a indicação das espécies, através de comunicação oral, experiência e tempo de trabalho, de profissionais e pesquisadores das áreas de Biologia, Engenharia Florestal e Instituto de Desenvolvimento Agropecuário (INDEA-MT), como também consultas bibliográficas, sempre buscando verificar a vulnerabilidade das espécies e ecossistemas.

As espécies foram separadas em seções: - madeireiras, medicinais, frutíferas, ornamentais e palmeiras.

Para classificação da espécie quanto à vulnerabilidade as categorias foram baseadas na União Internacional para Conservação da Natureza e dos Recursos Naturais (IUCN).

\section{Resultados}

São apresentadas 37 espécies da flora de Mato Grosso distribuídas em seções: madereira, medicinal, ornamental, frutíferas e palmeiras, de acordo com os critérios estabelecidos e suas respectivas categorias.

Tabela I - Espécies enquadradas na seção Madeireira com seu respectivo nome vulgar e categoria.

\begin{tabular}{lcc}
\hline Espécie & Nome vulgar & Categoria* \\
\hline Aspidosperma polyneuron M.Arg. & peroba-rosa & (V) \\
Astronium fraxinifolium Schott & gonçalo-alves & (V) \\
Astronium urundeuva (Fr.All.)Engl. & aroeira & (V) \\
Bertholletia excelsa H.B.K. & castanheira & (V) \\
Cedrella odorata L. & cedro-rosa & (V) \\
Cordia gerascanthus Jacq. & louro-preto & (V) \\
Cordia goeldiana Huber & freijó & (V) \\
Hymenaea courbaril L. & jatobá & (V) \\
Swietenia macrophylla King & mogno & (V) \\
Tabebuia spp. & ipês & (V) \\
Torresea acreana Ducke & cerejeira & (V) \\
\hline
\end{tabular}

(*) Categoria: (V) Vulnerável 
Tabela II - Espécies enquadradas na seção Medicinal com seu respectivo nome vulgar e categoria

\begin{tabular}{lcc} 
Espécie & Nome vulgar & Categoria* \\
\hline Brickelia piniifolia A.Gray & arnica & (E) \\
Cephaelis ipecacuanha (Brot.) A. Rich. & poaia & (E) \\
Lafoensia pacari St. Hil. & mangava-brava & (V) \\
Macrosiphonia velame M. Arg. & velame & (V) \\
Palicourea xanthophylla M. Arg. & douradinha & (V) \\
Serjania erecta Radlk. & cinco-folhas & (V) \\
Simaba ferruginea St. Hil. & calunga & (V) \\
Striphnodendron adstringens (Mart.) Coville & barbatimão & (V)
\end{tabular}

(*) Categoria: (V) Vulnerável

(E) Em perigo de Extinção

Tabela III. Espécies enquadradas nas seções Ornamental e Palmeiras com seu respectivo nome vulgar e categoria

\begin{tabular}{llc}
\hline Espécie & Nome vulgar & Categoria* \\
\hline \multicolumn{1}{c}{ Ornamentais } & & \\
Cattleya nobilior Rchb. f. & orquídea & (V) \\
Cattleya violacea (H.B.K.) Rolfe & orquídea & (V) \\
Chysis laevis Lindl. & orquídea & (R) \\
Erythryna vellutina Willd. & mulungu & (V) \\
Lycopodium carolinianum L. & pinheirinho de sala & (V) \\
Lycopodium cernuum L. & pinheirinho de sala & (V) \\
Notylia mirabilis C. Schweinf. & orquídea & (R) \\
Paepalanthus speciosus (Bong.) Koern & canela de ema & (E) \\
Pleurothalis brevipes Focke & orquídea & (R) \\
Zamia brogniartii Wedd & maquiné & (E) \\
$\quad$ Palmeiras & & \\
Copernicia australis Becc. & carandá & (V) \\
Mauritia vinifera M. & buriti & (V)
\end{tabular}

(*) Categoria: (V) Vulnerável

(E) Em Perigo de Extinção

(R) Rara

Tabela IV. Espécies enquadradas na seção Frutífera, com seu respectivo nome vulgar e categoria

\begin{tabular}{lcc}
\hline Espécie & Nome vulgar & Categoria* \\
\hline Caryocar brasiliense Camb. & pequi & (V) \\
Celtis spinosa Miq. & sarã & (V) \\
Inga spp. & ingá & (V) \\
Talisia subalbens (Mart.) Radlk. & cascudo & (V) \\
Talisia esculenta (St. Hil.) Radlk. & pitomba & (V) \\
Vitex cymosa Bert. & tarumã & (V) \\
\hline
\end{tabular}

$(*)$ Categoria: (V) Vulnerável 


\section{Discussão}

Segundo (Frankel \& Soulé, 1981) extinção é a falha de uma espécie ou população para manter-se por si através da reprodução. Ocorre tanto quando o último indivíduo morrer ou quando os indivíduos remanescentes são incapazes de produzir progênies viáveis ou férteis.

Segundo Dias (1989), não existem números precisos sobre taxas de extinção de espécies. Existem estimativas mostrando que, se continuarem as tendências atuais, o risco de perda é bastante significativo.

(Soulé \& Kohm, 1989) comentam que a ameaça de extinção em larga escala é mais crítica nas regiões tropicais do mundo, as quais contêm a maior diversidade de espécies. Perda de espécies nos trópicos está primariamente associada com conversão de habitats naturais para o uso humano, o que resulta na redução de habitats e fragmentação dos remanescentes.

Sobre a introdução de espécies exóticas, deve-se reconhecer que muitas dessas, acidentais ou intencionais, resultaram em importantes prejuízos para a qualidade ambiental, a diversidade biótica, o patrimônio genético e que muitas dessas espécies exóticas têm elevada capacidade de competir com sucesso com as espécies nativas, invadindo os ecossistemas naturais.

Devido a atividade humana direta ou indireta, cada vez mais é acelerado o número de espécies que estão desaparecendo. Em consequiência disto listas têm aparecido, apresentando espécies que estão ameaçadas de serem extintas, antes mesmo que a ciência possa pesquisar a utilidade direta ou indireta para a humanidade e função ecológica que desempenham no ecossistema onde vivem (Magnanini,1983).

Segundo Magnanini (1990), a maioria dos homens relutaria em reconhecer que, por mais útil que seja uma lavoura de trigo ou que, por mais formosa que seja uma cidade, também são áreas que desceram degraus no processo evolutivo natural.

É preocupante o contraste das estimativas da taxa de extinção na biosfera nos últimos 600 milhões de anos e para o ano 2000. Enquanto a taxa de extinção natural era de uma espécie ao dia, no ano 2000 essa poderá chegar a uma espécie por hora. São exatamente as espécies raras, as mais vulneráveis à extinção porque, em geral, são especializadas a um conjunto de restrito de fatores ambientais ou têm poderes limitados de se dispersar para outras áreas. Portanto, identificar diferentes formas de raridade é muito importante para o manejo e conservação da biodiversidade (Martins, 1992).

Segundo Cavalcanti (1981), no caso de plantas convém mencionar que há um interesse de ordem intencional no sentido de identificar e proteger espécies que, ou por serem naturalmente raras ou ameaçadas pela ação do homem estejam em vias de extinção.

O não adequado conhecimento da biologia das espécies, do seu potencial para diferentes usos e de variabilidade genética inter e intra populacionais existentes vêm levando à perda irreversível de recursos genéticos de inúmemeras espécies, antes que esses estudos ao menos tenham sido efetuados. 
Como ocorre em outras regiões brasileiras, a região Centro-Oeste, sofre também processos de alterações ambientais, principalmente em decorrência das atividades antrópicas (extração mineral e madeireira, assentamentos agrícolas, desmatamentos, culturas, etc) realizados de maneira irracional.

Atualmente, os índices de remoção da cobertura florestal do Estado de Mato Grosso ainda não atingiram níveis alarmantes, embora dados mais recentes indiquem a necessidade não só de um maior controle de desmatamento, como de maximizar a utilização do contingente de madeira retirada.

Da área total de $881.000 \mathrm{~km}^{2}$ do Estado, cerca de $6 \%$ já tiveram sua cobertura vegetal alterada (Ministério da Agricultura, 1984).

Este trabalho tem a intenção de alertar para o extrativismo excessivo das espécies madeireiras, as quais estão sendo retiradas de seus habitats naturais, tanto para industrialização quanto para formação de monoculturas, pecuárias e comercializadas sem que haja planejamento para reposição destas espécies.

Também alerta para o uso indiscriminado das plantas medicinais, que são retiradas do seu ambiente natural e comercializadas, acarretando na maioria dos casos o desaparecimento destas espécies e muitas vezes as plantas são retiradas inteiras (raiz, caule, folhas, flores) sem que o ciclo reprodutivo se complete.

Outro ítem que necessita de atenção, é o das plantas utilizadas na ornamentação. A retirada de algumas espécies, para a extração de madeira, exclusivas de algum tipo de solo específico ou de alguma formação vegetal também concorre para a extinção destas sem que tenham possibilidade de completar seu ciclo reprodutivo.

As espécies frutíferas utilizadas na alimentação do homem e de outros animais, bem como as de matas ciliares que servem como refúgios e alimentos para mamíferos e peixes.

Enfatiza-se as espécies dependentes de outras, ou animais para polinização e dispersão, sendo que se alguma das espécies sofrerem queda na população ou simplesmente desaparecerem, isto implicará diretamente na existência das dependentes. É bem extenso o ciclo de alterações que pode ocorrer e no entanto, o ser que não se inclui nesse meio - o homem- não tem nenhuma percepção disto.

Administrar as espécies significa melhorar as condições econômicas dos povos diretamente ligados a elas. Porém, para isto, é necessário investir em pesquisa e tecnologia, uma medida que os encarregados de tomar decisões têm a obrigação de empreender. Cada espécie que desaparece é uma opção a menos para gerações futuras (IUCN, 1980).

Segundo (Soulé \& Kohm, 1989) a necessidade da pesquisa como base para a conservação demonstra a interdependência entre pesquisa e ação e a impossibilidade da conservação efetiva na ausência de conhecimentos biológicos e sociais relevantes. A ênfase aos estudos de longo prazo não deve constituir motivo para adiar as ações. As respostas destas pesquisas fornecerão um entendimento mais profundo dos mecanismos que mantêm a riqueza biológica e a complexidade dos sistemas. Esta informação ajudará aos descendentes, na tarefa de proteger, restaurar a curto prazo fragmentos da biodiversidade. Muito pode ser feito para salvar esta fração significante do processo evolutivo. 


\section{Conclusões}

Dentro do contexto analisado, são apresentadas as seguintes recomendações: 1- Necessidade de estudar e pesquisar espécies ecologicamente significantes para direcionar-se o manejo e o monitoramento.

2- Promover o entrosamento entre pesquisadores de diversas áreas e órgãos responsáveis pela organização e fiscalização das áreas de conservação, para que medidas conservacionistas sejam tomadas quanto à seleção de espécies-chaves nos ecossistemas mais afetados e nas unidades de conservação.

3- Criar interesses sobre a importância e os valores da biodiversidade dentro da cultura popular com vistas a desacelerar a pressão sobre os ecossistemas e as áreas silvestres frágeis.

\section{Referências bibliográficas}

Cavalcanti, D. F. 1981. Plantas em Extinção no Brasil. Bol. FBCN (16):115-119.

Dias, S. M. 1989. A Importância da Atitude Conservacionista. Bol FBCN (24): 140-142.

Fonseca, G. A. B. 1991. Biodiversidade. In Meio Ambiente no Brasil: Mitos e Realidades. Ed. Jornal do Brasil. Rio de Janeiro.

Forero, E. 1989. Los Jardines Botanicos y la Conservacion de la Natureza. Acta bot. bras. 3 (2): 315-322.

Frankel \& Soulé. 1981. Conservation and Evolution. Cambridge University Press. 327 p.

Giulietti, A. M. \& Forero, E. 1990. "Work shop" Diversidade taxonômica das Angiospermas Brasileiras. Acta bot. bras. 4 (1):3-10.

IUCN. 1980. A Convenção sobre o Comércio Internacional de Espécies Ameaçadas da Fauna e Flora Silvestres. Bol. FBCN (16):98-104.

Magnanini, A. 1983. Uma Chave para Seleção de Espécies Vegetais ou Animais Ameaçadas de Extinção. Bol. FBCN (18):49-55.

Magnanini, A. 1990. A recuperação de áreas degradadas. Revta. bras. de geog. 52 (3):25-40.

Martins, R. P. 1992. Desafio Brasileiro é a Conservação da sua Biodiversidade. Revta. Caminhos, APUBH. 5:36-41.

Ministério da Agricultura/IBDF/Departamentro de Economia Florestal. 1984. Diagnóstico do Setor Florestal do Estado de Mato Grosso. 354p.

Soulé, M. \& Kohm, K. A. 1989. Research Priórites for Conservation Biology: Washington, D.C. Island Press, p.98. 